\title{
Sequence-Specific Aggregation Behavior of DNA-Carrying Colloidal Nanoparticles Prepared from $\operatorname{Poly}(\boldsymbol{N}$-isopropylacrylamide)-graft-Oligodeoxyribonucleotide
}

\author{
Mizuo MAEDA $^{\dagger}$ \\ Bioengineering Laboratory, RIKEN, 2-1 Hirosawa, Wako 351-0198, Japan
}

(Received September 3, 2006; Accepted September 12, 2006; Published October 19, 2006)

\begin{abstract}
Graft copolymers consisting of poly( $N$-isopropylacrylamide $)$ and single-stranded DNA were found to form DNA-carrying nanoparticles above physiological temperature. Aggregation of the nanoparticles was induced at relatively high salt concentration by the hybridization of surface-anchored DNA with full-match complementary DNA. In contrast, single-base mismatches at the distal end stabilized the colloidal dispersion so that the dispersion remained transparent. The phenomenon is applicable to SNP typing. [doi:10.1295/polymj.PJ2006107]

KEY WORDS DNA / Graft Copolymer / Nanoparticle / Poly $(N$-isopropylacrylamide $)$ / SNP Typing /
\end{abstract}

Colloidal particles carrying single-stranded DNA are useful in the field of molecular biology. ${ }^{1}$ Most particles are latex-based and can be used for the sequence-specific separation of DNA or RNA as well as DNA detection. Recently, DNA-carrying gold nanoparticles were reported to form particle assemblies spontaneously through the hybridization with complementary DNA. ${ }^{2}$ This is important not only for a material construction but also for a colorimetric DNA detection. DNA-carrying colloidal particles reported so far were commonly prepared by a two-step procedure, i.e., plain colloidal particle preparation followed by DNA immobilization to particles. However, it is not easy to connect single-stranded DNA chains on the surface of particles in a controlled, efficient, and reproducible manner. Especially the preparation of densely modified particles is rather difficult.

The preparation of colloidal particles with a coreshell structure through the self-organization of amphiphilic copolymers have received much attention. ${ }^{3}$ In this method, particles are prepared by solvent exchange from nonselective solvent to selective solvent. Amphiphilic block and graft copolymers containing a hydrophilic segment and hydrophobic one have been studied for their ability to form a stable aqueous dispersion of the self-assemblies. However, the method needs a certain common solvent in which both parts of the copolymer are soluble. This is a problem when preparing DNA-carrying particles, since DNA is soluble only in water but not in any non-aqueous solvents which are good for the hydrophobic part of the copolymer.

Recently, an alternative preparation method to aque- ous colloidal particles has been reported using a temperature-responsive polymer, poly $(N$-isopropylacrylamide). ${ }^{4}$ Poly $(N$-isopropylacrylamide) (PNIPAAm) is a water-soluble polymer that shows a reversible temperature-induced phase transition..$^{5}$ The temperature at which this transition occurs is called the lower critical solution temperature (LCST). Below LCST, the polymer chain is hydrated and adopts an extended coil conformation, while above the LCST, the polymer is dehydrated to give a globular conformation, resulting in intermolecular aggregates. It has been reported that PNIPAAm-containing block ${ }^{6}$ and graft $^{7}$ copolymers form colloidal nanoparticles through the coil-globule transition of PNIPAAm segments. These particles have structures of a dehydrated PNIPAAm core surrounded by hydrophilic polymer segments so that the particles stably disperse in aqueous media. Since PNIPAAm is soluble in water below LCST, its copolymer can be prepared totally in aqueous system. This is especially important when the other segment is a biological macromolecule such as proteins and DNA.

Another interesting feature of PNIPAAm is that copolymerization with different functional monomers may result in change of LCST. In general, the incorporation of hydrophobic comonomers leads to a lower LCST and hydrophilic comonomers to a higher LCST. The introduction of charge also affects the LCST. These unique features have been utilized for the intelligent switch of stimuli-responsive systems. PNIPAAm functionalized with crown ether moieties was reported to have the cation-dependent LCST. ${ }^{8}$ The polymer has been used as an ion-gating swich of a polymer membrane. ${ }^{9}$ The flux of aqueous ionic

${ }^{\dagger}$ To whom correspondence should be addressed (Tel: +81-48-467-9311, Fax: +81-48-462-4658, E-mail: mizuo@riken.jp). 


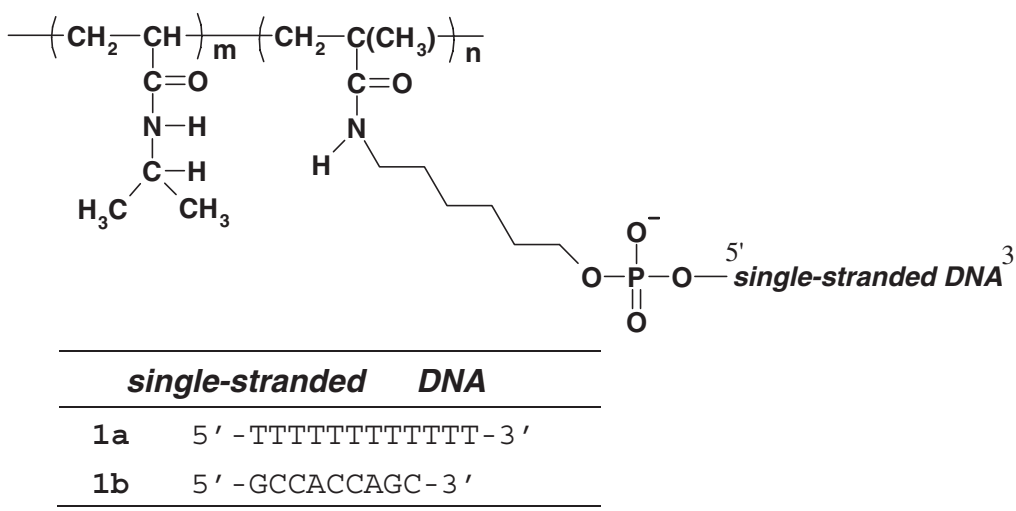

Scheme 1. Chemical structure of poly( $N$-isopropylacrylamide)-graft-DNA (1).

solutions through the membrane was dependent specifically on cation species. A glucose-responsive polymer was developed from PNIPAAm containing phenylboronate functions which form reversible covalent complexes with glucose. ${ }^{10}$ The covalent binding of glucose raised the LCST by $5{ }^{\circ} \mathrm{C}$ at around physiological $\mathrm{pH}$.

The above two features of PNIPAAm may be used for the preparation of nanoparticles whose aggregation state changes in response to an external stimulus. Such intelligent colloidal systems are very promising as a carrier for drug delivery systems, since the change of the colloidal assembly may result in the release of encapsuled drugs. This may also be useful for analytical or diagnostic systems with an amplification function when some reporter molecules such as fluorescent dye are embedded in the colloidal particles. However, in previously reported PNIPAAm-based systems, molecular recognition functions are limited to those with simple structures.

As a more sophisticated functionality, we have chosen single-stranded DNA since it is a hydrophilic macromolecule due to its anionic phosphodiester backbone and forms double-helix exclusively with its complementary DNA. LCST of PNIPAAm having DNA branches can be modified when the branches form double helix, because the molecular conformation and ionic property should be different between single strand and double helix. If this is the case, the PNIPAAm-DNA copolymer should be applicable to the detection of the specific DNA.

This paper describes a one-step preparation of DNA-carrying colloidal nanoparticle through the self-organization of the copolymer (1, Scheme 1). ${ }^{11}$ $\mathbf{1}$ is composed of PNIPAAm main chain and DNA graft chains, so that it forms above LCST a colloidal particle with PNIPAAm core surrounded by hydrophilic DNA. LCST did not change significantly upon DNA hybridization. However, the nanoparticles showed aggregation spontaneously upon hybridization with complementary DNA above LCST $\left(c a .37^{\circ} \mathrm{C}\right)$ and at certain salt concentration (typically, $0.5 \mathrm{M}$ $\mathrm{NaCl}) .{ }^{12}$ The process was observed as turbidity increase of the dispersion, suggesting that the nanoparticle system would be applicable to turbidimetric detection of DNA. This differs from the crosslinking aggregation of DNA-functionalized nanoparticles induced by complementary DNA. ${ }^{1 \mathrm{~d}, 2 \mathrm{a}}$ The present aggregation takes place only with the exactly-matched DNA in terms not only of sequence but length to give duplex having blunt end. Although the aggregation seems due to the stability decrease of the colloidal dispersion induced by the hybridization, i.e., doublehelix formation on the nanoparticle surface, the mechanism still remains unclarified. ${ }^{13}$ This paper presents unpublished results in the early stage of our study and describes the specific aggregation behavior of DNA-carrying colloidal nanoparticles.

\section{DNA-CARRYING NANOPARTICLES}

As of PNIPAAm having DNA branches, 1a was prepared by copolymerization between $\mathrm{N}$-isopropylacrylamide (NIPAAm) and DNA macromonomer. DNA macromonomer was synthesized by coupling reaction between methacryloyloxysuccinimide and amino-linked $\mathrm{dT}_{12}$ having aminohexyl linker at its $5^{\prime}$-terminus, as reported previously. ${ }^{14}$ Polymerization was carried out at $25^{\circ} \mathrm{C}$ for $1 \mathrm{~h}$ using ammonium persulfate and $N, N, N^{\prime}, N^{\prime}$-tetramethylethylenediamine.

Figure 1 shows temperature dependence of \%transmittance at $500 \mathrm{~nm}$ of aqueous solution of 1a $(0.1 \mathrm{mg} / \mathrm{mL}$ in $500 \mathrm{mM} \mathrm{NaCl})$. Subtle change in transmittance was observed at $36^{\circ} \mathrm{C}$, which agrees with the fact that the endothermic peak was observed at $37^{\circ} \mathrm{C}$ in DSC measurement. However the solution was still transparent at and over that temperature. Dynamic light scattering measurement of the solution at $40^{\circ} \mathrm{C}$ suggested the formation of nanoparticles having the hydrodynamic radius $\left(R_{\mathrm{h}}\right)$ of $25 \mathrm{~nm} . M_{\mathrm{w}}$ of the colloidal particles was determined by static light scattering measurement to be $8.6 \times 10^{6}$. $M_{\mathrm{w}}$ of 1 a was $2.6 \times$ 


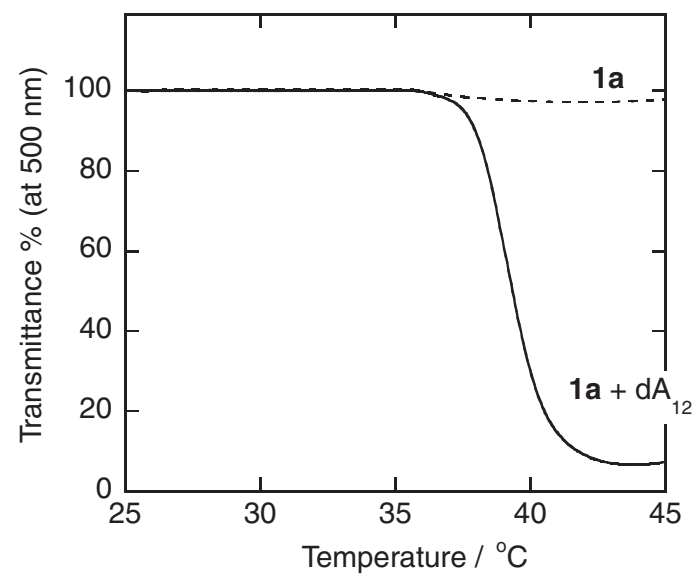

Figure 1. Temperature dependence of transmittance at 500 $\mathrm{nm}$ of aqueous solution of $1 \mathbf{a}$ in $500 \mathrm{mM} \mathrm{NaCl} / 10 \mathrm{mM}$ Tris$\mathrm{HCl}(\mathrm{pH} \mathrm{7.4)}$ in the absence or presence of the complementary DNA $\left(\mathrm{dA}_{12}\right)$. Copolymer concentration was $0.1 \mathrm{mg} / \mathrm{mL}$.

$10^{5}$ and the mole fraction of $\mathrm{dT}_{12}$ macromonomer unit in 1a was $0.36 \mathrm{~mol} \%$ so that 1a contained $c a .7$ branches from $\mathrm{dT}_{12}$. The nanoparticle may thus consist of $c a .30$ molecules of 1a and each particle may have $c a .200$ chains of $\mathrm{dT}_{12}$ on it, assuming that all DNA branches are located on the surface.

Since our primary interest was whether LCST of $\mathbf{1}$ changes upon hybridization with the complemantary DNA to form double-helical branches in the graft copolymer, we added $\mathrm{dA}_{12}$ to a solution of 1a. LCST did not change substantially. However, the solution became turbid at around $36^{\circ} \mathrm{C}$ as shown in Figure 1 . A plausible and simple explanation for the aggregation may be complementary adenine-thymine hydrogen bondings. Such multiple interactions should result in crosslinking of nanoparticles by $\mathrm{dA}_{12}$ strands. To examine this hypothesis, we studied the effects of chain length of oligo(dA) on aggregation. Figure 2 shows a time-course of $\%$-transmittance at $500 \mathrm{~nm}$ of aqueous solution of $1 \mathbf{a}$ at $40{ }^{\circ} \mathrm{C}$ after the addition of $\mathrm{dA}$ oligomers. With the addition of $\mathrm{dA}_{12}$, the solution became turbid rapidly within a few minutes. However, no transmittance change was observed with the addition of $\mathrm{dA}_{18}$ or $\mathrm{dA}_{24}$. These are longer than $\mathrm{dA}_{12}$ so that the crosslinking could have formed more effectively. Aggregation in the presence of $\mathrm{dA}_{12}$ did not seem due to crosslinking but a different mechanism.

\section{SALT-DEPENDENT AGGREGATION}

In general, a colloidal dispersion in which nanoparticles are stabilized by electrostatic repulsion makes aggregate at a relatively high salt concentration. We studied the stability of the DNA-carrying nanoparticles when changing the concentration of salt $(\mathrm{NaCl})$.

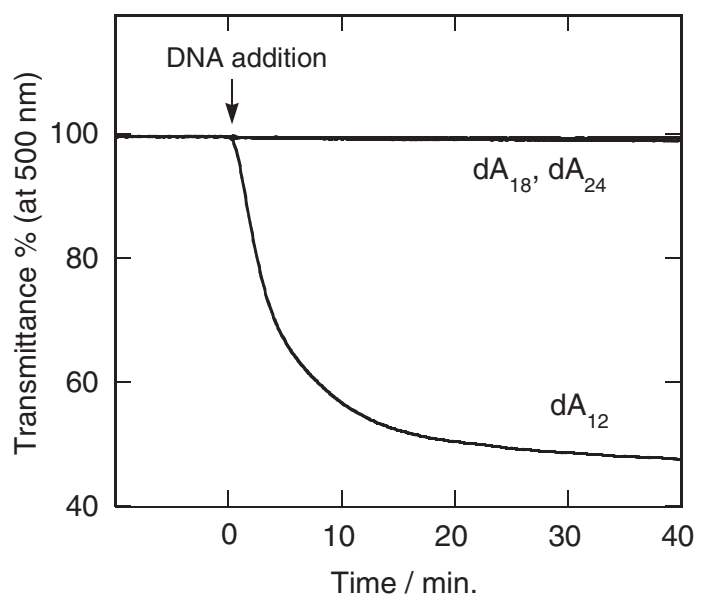

Figure 2. Time course of transmittance at $500 \mathrm{~nm}$ of the nanoparticle dispersion from 1a after the addition of target DNA $\left(\mathrm{dA}_{12}, \mathrm{dA}_{18}\right.$ or $\left.\mathrm{dA}_{24}\right)$ at $40{ }^{\circ} \mathrm{C}$ in $500 \mathrm{mM} \mathrm{NaCl} / 10 \mathrm{mM}$ Tris$\mathrm{HCl}$ ( $\mathrm{pH}$ 7.4). Copolymer concentration was $0.1 \mathrm{mg} / \mathrm{mL}$.

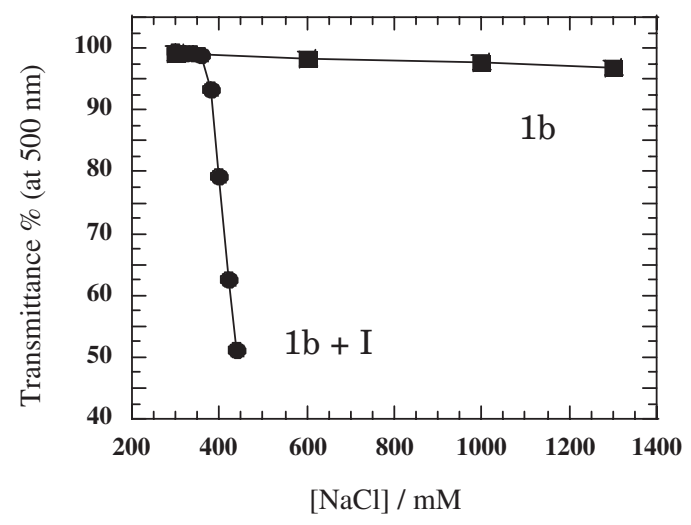

Figure 3. Transmittance at $500 \mathrm{~nm}$ of the nanoparticle dispersion prepared from $\mathbf{1 b}$ at $40^{\circ} \mathrm{C}$ as a function of $\mathrm{NaCl}$ concentration in the absence or presence of the complementary DNA (I). Copolymer concentration was $0.1 \mathrm{mg} / \mathrm{mL}$.

Figure 3 shows the \%-transmittance of the nanoparticle dispersion at $500 \mathrm{~nm}$ after mixing with $\mathrm{NaCl}$ solution. The graft copolymer in this experiment has the structure of $\mathbf{1 b} . M_{\mathrm{w}}$ of $\mathbf{1 b}$ was $4.0 \times 10^{5}$ and the mole fraction of DNA macromonomer unit was $0.35 \mathrm{~mol} \%$, indicating that $\mathbf{1 b}$ contains $c a$. 10 DNA molecules. To form the core-shell colloidal particle from $\mathbf{1 b}$, the temperature of the solution was raised to $40^{\circ} \mathrm{C} . M_{\mathrm{w}}$ and $R_{\mathrm{h}}$ of the colloidal particles were determined to be $8.7 \times 10^{6}$ and $23 \mathrm{~nm}$, respectively. Thus the particle has $c a .240$ DNA chains on its surface. Figure 3 clearly indicates that the suspension of DNA-carrying nanoparticles prepared from the copolymer $\mathbf{1 b}$ is extremely stable even in at high salt concentration of $1.3 \mathrm{M} \mathrm{NaCl}$.

The stability of the colloidal particles was also examined in the presence of complementary DNA (sequence $\mathbf{I}$ in Table I). As shown in Figure 3, the 
Table I. Sequences of DNA examined and melting temperatures of their duplex $\left(T_{\mathrm{m}}\right)^{*}$

\begin{tabular}{clcc}
\hline Code & Sequence $\left(3^{\prime} \rightarrow 5^{\prime}\right)$ & $T_{\mathrm{m}} /{ }^{\circ} \mathrm{C}$ & Note \\
\hline I & C G G T G G T C G & 54.3 & complementary \\
II & C G G T A G T C G & 29.1 & inside mismatch \\
III & C G G T G G T C G $\underline{\mathbf{A}}$ & 58.1 & terminal addition \\
IV & C G G T G G T C $\underline{\mathbf{A}}$ & 49.6 & terminal mismatch \\
V & C G G T G G T C $\underline{\mathbf{T}}$ & 45.8 & terminal mismatch \\
VI & C G G T G G T C $\underline{\mathbf{C}}$ & 46.2 & terminal mismatch \\
\hline
\end{tabular}

*: Melting temperatures of duplex between each DNA (I-VI) and 5'-GCCACCAGC- $3^{\prime}$ in $1.0 \mathrm{M} \mathrm{NaCl} / 10 \mathrm{mM}$ Tris-HCl buffer ( $\mathrm{pH}$ 7.4). The duplex DNA concentration was $3 \mu \mathrm{M}$ in strand. Heating rate was $0.5^{\circ} \mathrm{C} / \mathrm{min}$.

transimittance of the particle dispersion in the presence of I decreased steeply at $400 \mathrm{mM}$ of $\mathrm{NaCl}$. As seen in Figure 4a, no change was observed in the presence of II, a one-base mismatched sequence. This means that DNA-carrying nanoparticles recognize the exactly-matched DNA exclusively and report it with turbidity change. The instability of colloidal particles in the presence of I should be ascribed to the fully-matched double helical structure formed by the selective hybridization of $\mathbf{I}$ with the surface DNA, since the sequence should not make crosslinking between nanoparticles.

To confirm this, we investigated the temperature effects on the particle aggregate formed in the presence of $\mathbf{I}$. As the temperature increased, the transmittance of the dispersion increased steeply in the narrow temperature range around $48^{\circ} \mathrm{C}$ as shown in Figure $5 \mathrm{~b}$. The temperature range of this redispersion process was included in that of the dissociation of free duplex DNA ( $c a .40-60^{\circ} \mathrm{C}$ as shown in Figure 5a and thus, the redispersion can be attributed to the dissociation of DNA duplex into single strand on the particle surface. These results strongly suggest that the stability of colloidal particle decreases drastically when the particle surface is covered with double helical DNA in spite of its increased number of anionic charges.

Although the mechanism is not fully understood, we suppose that conformational transition of the surface DNA plays an essential role. Formation of the double helix makes the conformation tighter and stiffer. This transition may reduce the repulsive interaction between nanoparticles as follows; (1) electrostatic repulsion may be decreased by the screening effect, because the tight conformation condenses anionic charge due to DNA phosphate and raises the binding constant with counter cations, and (2) steric repulsion may be reduced, because the stiffening of the DNA lowers the entropic effect. If this is the case, we may understand the results in Figure 2, where $\mathrm{dA}_{12}$ made the colloidal dispersion from 1a unstable to give aggregation, whereas $\mathrm{dA}_{18}$ and $\mathrm{dA}_{24}$ did not. In the case of $\mathrm{dA}_{18}$ and $\mathrm{dA}_{24}$, protruding single stranded region should remain on the particle surface even after double helix formation with surface-anchored $\mathrm{dT}_{12}$, stabilizing the colloidal dispersion.

The question arises as to how many nucleotide units are needed as a protruding single strand to stabilize the colloidal dispersion from 1. The answer is one nucleotide addition being enough to stabilize the colloidal system as seen in Figure $4 \mathrm{a}$ (for sequence III in Table I). The presence of DNA III, which has one additional unit of $\mathrm{dA}$ at the $5^{\prime}$ terminus of $\mathbf{I}$, did not affect the transmittance at all at $0.3-1.3 \mathrm{M} \mathrm{NaCl}$. $T_{\mathrm{m}}$ values in Table I suggest that III should form a much more stable duplex with the surface-anchored DNA than I. This is in contrast with case II in the same Figure 4a, where most surface-anchored DNA chains should remain in their single-stranded form to stabilize the particle dispersion as described above.

\section{TERMINAL MISMATCH SENSITIVITY}

Even one nucleotide protruding was not necessary for the colloidal stability. Figure $4 \mathrm{~b}$ shows the effects

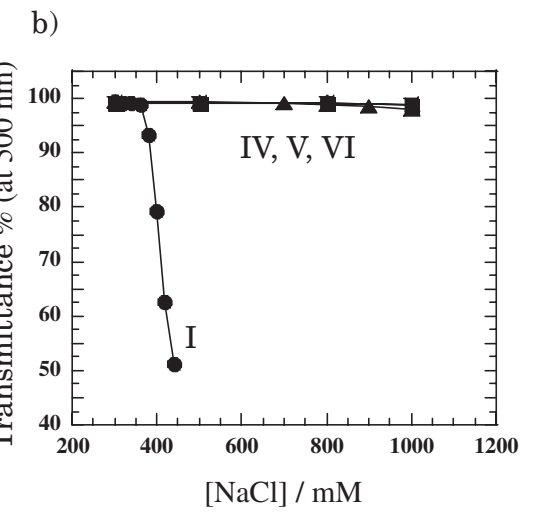

Figure 4. Transmittance at $500 \mathrm{~nm}$ of the nanoparticle dispersion prepared from $1 \mathbf{b}$ at $40{ }^{\circ} \mathrm{C}$ as a function of $\mathrm{NaCl}$ concentration in the presence of DNA I-VI. Copolymer concentration was $0.1 \mathrm{mg} / \mathrm{mL}$. 


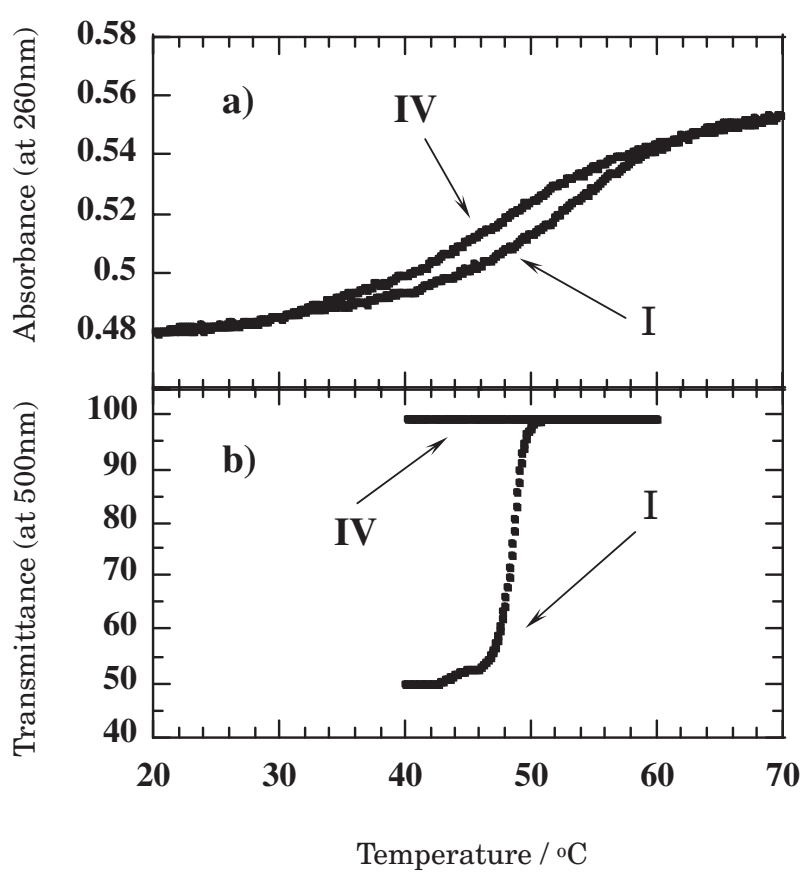

Figure 5. a) Melting curves for duplex between DNA I or III and 5'-GCCACCAGC-3' in $500 \mathrm{mM} \mathrm{NaCl} / 10 \mathrm{mM}$ Tris- $\mathrm{HCl}$ buffer (pH 7.4). Free duplex DNA concentration was $3 \mu \mathrm{M}$ in strand. Heating rate was $0.5^{\circ} \mathrm{C} / \mathrm{min}$. b) Temperature dependence of the transmittance at $500 \mathrm{~nm}$ of the nanoparticle dispersion from 1b in the presence of I or III. Copolymer concentration was $0.1 \mathrm{mg} / \mathrm{mL}$.

of the $5^{\prime}$-terminally mismatched DNA ( $\mathbf{I V}, \mathbf{V}$, and VI in Table I) present in the aqueous dispersion of nanoparticles from $1 \mathrm{~b}$ at $40^{\circ} \mathrm{C}$. The mismatch of the added DNA at $5^{\prime}$ terminus resulted in totally stable transparent dispersion. This clearly indicates that nanoparticles make response exclusively with the fully-matched DNA (I). Nanoparticles are thus promising for the single nucleotide polymorphisms (SNP) sensing.

This finding is confirmed in Figure 5b, where DNA IV is shown to give a transparent suspension at $40^{\circ} \mathrm{C}$. DNA IV is suggested from the melting profile (Figure 5a) to form a duplex with the surface-anchored probe DNA at $40^{\circ} \mathrm{C}$ to a similar degree of duplex formation for DNA I at around $45^{\circ} \mathrm{C}$, where DNA I makes the system turbid as seen from Figure $5 \mathrm{~b}$. The stability of present colloidal system depends on the terminal structure of surface-anchored duplex but not on the degree of hybridization. The $5^{\prime}$ terminus means the distal end of surface DNA which should affect the colloidal stability of nanoparticles.

Terminal-mismatch sensitivity was also seen in DNA-modified gold nanoparticles. In the case of gold nanoparticles, a similar salt-dependent aggregation experiments can be conducted at $25^{\circ} \mathrm{C}$ and be detected by clear colorimetric change from red to purple. ${ }^{15}$ Full match DNA only turned the clear suspension to purple. The system was applied to the products from the single-base primer extension reaction for SNP typing. ${ }^{16}$ Optimization of gold particle diameter was carried out at $15-50 \mathrm{~nm} .{ }^{17}$ Surface plasmon resonance imaging has been applied to highly sensitive detection of DNA-modified gold nanoparticles because the aggregate formed in the presence of the full-match DNA target was found deposited on the substrate surface like poly(dimethylsiloxane) (PDMS). ${ }^{18}$ SNP sensing was demonstrated on a PDMS microchip device using this terminal-sensitive aggregation phenomenon.

\section{CONCLUSION}

Aggregation of nanoparticles has been applied to analytical methods of various substances including DNA, antibodies, lectins, and metal ions. Most methods are based on crosslinking of particles by affinity binding between ligand and substrate, one of which is immobilized on the particle and the other is an analyte to crosslink the particles. Our system does not rely on crosslinking but stability change of colloidal dispersion. Our new finding should be applicable to sensitive and reliable DNA sensing systems.

Acknowledgment. The author thanks Drs Takeshi Mori and Zhonglan Tang of Kyushu University and Dr Tohru Takarada of RIKEN for their large contribution to this study. The coauthors of our papers cited below are also acknowledged. This work was supported in part by a grant-in-Aid for Scientific Research from Ministry of Education, Culture, Sports, Science, and Technology of Japan.

\section{REFERENCES}

1. a) K. Kuribayashi-Ohta, S. Tamatsukuri, M. Hikata, C. Miyamoto, and Y. Furuichi, Biochim. Biophys. Acta, 1156, 204 (1993).

b) T. Imai, Y. Sumi, M. Hatakeyama, K. Fujimoto, H. Kawaguchi, N. Hayashida, K. Shiozaki, K. Terada, H. Yajima, and H. Handa, J. Colloid Interface Sci., 177, 245 (1996).

c) M. Hatakeyama, H. Iwato, S. Hanashima, K. Nakamura, and H. Kawaguchi, Colloids Surf., A, 153, 445 (1999).

d) T. Ihara, K. Kurohara, and A. Jyo, Chem. Lett., 28, 1041 (1999).

2. a) C. A. Mirkin, R. L. Letsinger, R. C. Mucic, and J. J. Storhoff, Nature, 382, 607 (1996).

b) C. L. Loweth, W. B. Caldwell, X. Peng, A. P. Alivisatos, and P. G. Schultz, Angew. Chem., Int. Ed., 38, 1808 (1999). c) R. Elghanian, J. J. Storhoff, R. C. Mucic, R. L. Letsinger, and C. A. Mirkin, Science, 277, 1078 (1997).

3. a) Z. Gao, S. K. Varshney, S. Wong, and A. Eisenberg, Macromolecules, 27, 7923 (1994).

b) K. Prochazka, T. J. Martin, P. Munk, and S. E. Webber, 
Macromolecules, 29, 6518 (1996).

c) M. Li, M. Jiang, L. Zhu, and C. Wu, Macromolecules, 30, 2201 (1997).

d) K. Kataoka, A. Ishihara, A. Harada, and H. Miyazaki, Macromolecules, 31, 6071 (1998).

4. a) M. D. C. Topp, P. J. Dijkstra, H. Talsma, and J. Feijen, Macromolecules, 30, 8518 (1997).

b) X. Qiu and C. Wu, Macromolecules, 30, 7921 (1997).

c) D. Liang, S. Zhou, L. Song, V. S. Zaitsev, and B. Chu, Macromolecules, 32, 6326 (1999).

5. H. G. Schild, Prog. Polym. Sci., 7, 163 (1992).

6. a) J. Virtanen, S. Holappa, H. Lemmetyinen, and H. Tehnu, Macromolecules, 30, 8518 (1997).

b) M. Arotçaréna, B. Heise, S. Ishaya, and A. Laschewsky, J. Am. Chem. Soc., 124, 3787 (2002).

c) J. Virtanen, M. Arotçaréna, B. Heise, S. Ishaya, A. Laschewsky, and H. Tenhu, Langmuir, 18, 5360 (2002).

d) Č. Koňák, D. Oupický, V. Chytrý, and K. Ulbrich, Macromolecules, 33, 5318 (2000).

7. a) C. Wu and X. Qiu, Phys. Rev. Lett., 80, 620 (1998).

b) J. Virtanen, C. Baron, and H. Tenhu, Macromolecules,
33, 336 (2000).

8. M. Irie, Y. Misumi, and T. Tanaka, Polymer, 34, 4531 (1993).

9. T. Ito, T. Hioki, T. Yamaguchi, T. Shinbo, S. Nakao, and S. Kimura, J. Am. Chem. Soc., 124, 7840 (2002).

10. A. Matsumoto, S. Ikeda, A. Harada, and K. Kataoka, Biomacromolecules, 4, 1410 (2003).

11. T. Mori and M. Maeda, Polym. J., 33, 830 (2001).

12. T. Mori and M. Maeda, Polym. J., 34, 624 (2002).

13. T. Mori and M. Maeda, Langmuir, 20, 313 (2004).

14. T. Mori, D. Umeno, and M. Maeda, Biotechnol. Bioeng., 72, 261 (2000).

15. K. Sato, K. Hosokawa, and M. Maeda, J. Am. Chem. Soc., 125, 1547 (2003).

16. K. Sato, K. Hosokawa, and M. Maeda, Nucleic Acids Res., 33, e4 (2005).

17. K. Sato, M. Onoguchi, Y. Sato, K. Hosokawa, and M. Maeda, Anal. Biochem., 350, 162 (2006).

18. Y. Sato, K. Sato, K. Hosokawa, and M. Maeda, Anal. Biochem., 355, 125 (2006).

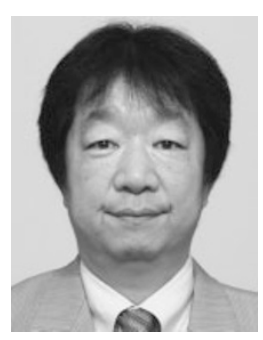

Mizuo Maeda received his Ph.D. form the University of Tokyo in 1983. He was a Research Associate (Assistant Professor) in the laboratory of synthetic polymer chemistry at the University of Tokyo since 1983 through 1988. Then he moved to Kyushu University as an Associate Professor of Synthetic Chemistry. Prior to coming to RIKEN Institute as a Chief Scientist in 2001, Dr Maeda was Professor of Materials Physics and Chemistry at Kyushu University since 1995. He is now Director of Bioengineering Laboratory in RIKEN. Since 2006, Dr Maeda also has a laboratory in the Department of Advanced Materials Science, School of Frontier Sciences, the University of Tokyo as a Professor. His research interests center on polymer chemistry, analytical chemistry, and biomaterials science. He received the Award of the Society of Polymer Science, Japan (2004). 